\title{
Synthesis and Characterization of Cobalt(II), Nickel(II) and Copper(II) Complexes with Nitrogen-Oxygen Donor Ligand
}

\author{
B. K. RAI ${ }^{*}$, VINEETA SINGH ${ }^{1}$, PUJA SINHA ${ }^{2}$, S. N. VIDYARTHI ${ }^{3}$, \\ SHASHI BHUSHAN SAHI ${ }^{3}$, ASHOK PANDEY ${ }^{4}$ and AMIT $^{3}$ \\ *Department of Chemistry, L. N. T. College, B. R. A. Bihar University, Muzaffarpur, India. \\ 'B.N.R. Guljarbag, Patna, India. \\ ${ }^{2}$ FNS Academy, Guljarbag, Patna, India. \\ ${ }^{3}$ University Department of Chemistry, J. P. University, Chapra, India. \\ ${ }^{4} \mathrm{M}$. H. Degree College, Tarwara, Siwan, India. \\ ${ }^{*}$ Corresponding author E-mail : binodkr_rai@yahoo.co.in \\ http://dx.doi.org/10.13005/ojc/300363
}

(Received: April 10, 2014; Accepted: May 20, 2014)

\begin{abstract}
The complexes of $\mathrm{ML}_{2}$ were synthesized where $\mathrm{M}=\mathrm{Co}(\mathrm{II}), \mathrm{Ni}(\mathrm{II})$ and $\mathrm{Cu}(\mathrm{II})$ and $\mathrm{L}=2-\mathrm{Butyl}$ thioquinazoline 4 (3H)- semicarbazone (BTQS). The ligand have been synthesized by condensation of thioquinazoline-4(3H)-one with semicarbazide hydrochlande characterized by molar mass, elemental analysis, Infrared spectra, electronic spectra, magnetic susceptibility and molar conductance measurements. The ligand BTQS acts as neutral bidentate chelating agent and coordinated to metal ions through azomethine nitrogen and carbonyl oxygen of semicarbazone moiety. The remaining Coordination centres are satisfied by anions such as $\mathrm{Cl}^{-}, \mathrm{Br}, \mathrm{I}^{-}$and $\mathrm{NO}_{3}^{-}$.
\end{abstract}

Key words : Schiff base / BTQS / Co(II), Ni(II) and Cu(II) / Complexes

\section{INTRODUCTION}

Transition metal complexes of Schiff base have been intensely investigated by Coordination chemists due to their interesting structural properties and their wide ranging applications ${ }^{1-5}$, The coordination ability of Schiff bases with transition element, particularly with first row, afford the study of the metals in such system. Keeping the above facts in mind and in continuation of our recent work ${ }^{6-21}$ we now, present the results of our investigations on the synthesis, spectral and the theoretical studies of $\mathrm{Co}(\mathrm{II}), \mathrm{Ni}(\mathrm{II})$ and $\mathrm{Cu}$ (II) complexes with ligand, 2-butyl thioquinazoline $4(3 \mathrm{H})$ semicarbazone (BTQS).

\section{EXPERIMENTAL}

All the reagents herein used were of analytical grade. The metal contents of the complexes were estimated using standard procedures ${ }^{22}$. The IR spectra (Table-2) were recorded on PerkinElmer-577 spectrophoto-meter using $\mathrm{KBr}$ disc. 
Magnetic susceptibility were measured on Gouy balance using $\mathrm{Hg}\left[\mathrm{CO}(\mathrm{NCS})_{4}\right]$ as a calibrant . Electronic spectra were recorded on Systronics conductivitymeter model 303 using DMF as a solvent.

Preparation of the Ligand :

Ethanolic solution of 2-butyl thioquinazoline $4(3 \mathrm{H})$ one $(0.01 \mathrm{~m})$ was treated with semicarbazide hydrochloride $(0.01 \mathrm{~m})$ dissolved in minimum amount of sodium acetate in ethanol. The resulting mixture was heated for 2 and half hour with occassional stirring. The product crystallized from ethanol and dried. m.p. $263 \pm 1^{\circ} \mathrm{C}$. Yield $65 \%$.

\section{Preparation of the complexes}

The complexes of $\mathrm{Cu}(\mathrm{II}), \mathrm{Co}(\mathrm{II})$ and $\mathrm{Ni}(\mathrm{II})$ have been prepared by reacting solution of metal halides with solutions of the ligand BTQS in molar ratio 1:2. The solid coloured complexes which was separated on cooling were filtered, washed with ethanol, dried in oven. Yield in all cases $60-65 \%$.

\section{RESULTS AND DISCUSSION}

\section{I.R. Spectra}

IR spectra of the ligand and complexes were recorded on Perkin Elmer Spectrophotometer Model 577 using $\mathrm{KBr}$ disc.

The IR spectra of the ligand exhibit strong and broad band at $1560 \mathrm{~cm}^{-1}$ assignable $\mathrm{e}^{23-25}$ to $v_{\mathrm{C}=\mathrm{N}}$. The band is shifted to lower wave number after complex formation, proposes involvement of azomethine $\mathrm{N}$ in the bonding with metal ions. The appearance of a band in far IR region at 425-395 $\mathrm{cm}^{-1}$. In the complexes assignable ${ }^{24-26}$ to $\mathrm{v}_{\mathrm{M}-\mathrm{N}}$. The IR spectra of the ligand exhibits strong and broad band at $1760 \mathrm{~cm}^{1}$ assignable $e^{25-28}$ to $v_{\mathrm{C}=0}$. This band undergoes to shift after complex formation, proposes coordination of metal ion through carbonyl oxygen. It is further supported by the appearance of a new far IR band at 525-505 $\mathrm{cm}^{-1}$ in the complexes which is assignable $24-26$ to $v_{\mathrm{M}-0}$. The linkage with halogen is indicated by the appearance of another band in the far IR region $320-280 \mathrm{~cm}^{1}$ assigned ${ }^{24-26}$ to $\mathrm{v}_{\mathrm{M}-\mathrm{X}}\left(\mathrm{X}=\mathrm{Cl}^{-}\right.$, $\mathrm{Br}^{-}$or $\left.\mathrm{I}^{-}\right)$. The coordination with halogen is supported by the low molar conductivity of the complexes in the range 11.2-13.7 $\mathrm{ohm}^{-1} \mathrm{~cm}^{2} \mathrm{~mol}^{-1}$.

Nitrate complexes show characteristic medium intensity bands at 1360 and $1180 \mathrm{~cm}^{-1}$ with a separation $140 \mathrm{~cm}^{-1}$ due to monodentate linkage of nitrate groups. Combination band at $1660 \mathrm{~cm}^{-1}$ and $1640 \mathrm{~cm}^{-1}$ with a separation of $20 \mathrm{~cm}^{-1}$ conforming the monodentate behavior of the nitrate ${ }^{29}$ group.

\section{Electronic Spectra and Magnetic Susceptibility of the Complexes}

The Co(II) complexes exhibit two spectral bands in the region at 13400-12860 $\mathrm{cm}^{-1}$ and $2100-20300 \mathrm{~cm}^{-1}$ assigned to the transitions, ${ }^{4} \mathrm{~T}_{1 g}(\mathrm{~F}) \rightarrow{ }^{4} \mathrm{~A}_{2 \mathrm{~g}}(\mathrm{~F})$ and ${ }^{4} \mathrm{~T}_{1 \mathrm{~g}}(\mathrm{~F}) \rightarrow{ }^{4} \mathrm{~T}_{1 \mathrm{~g}}(\mathrm{P})$ proposing octahedral ${ }^{30,31}$ geometry. The proposed geometry of Co(II) complexes are further supported by the high magnetic susceptibility value in the range 4.92-5.12 B.M. The $\mathrm{Ni}(\mathrm{II})$ complexes display three spectral

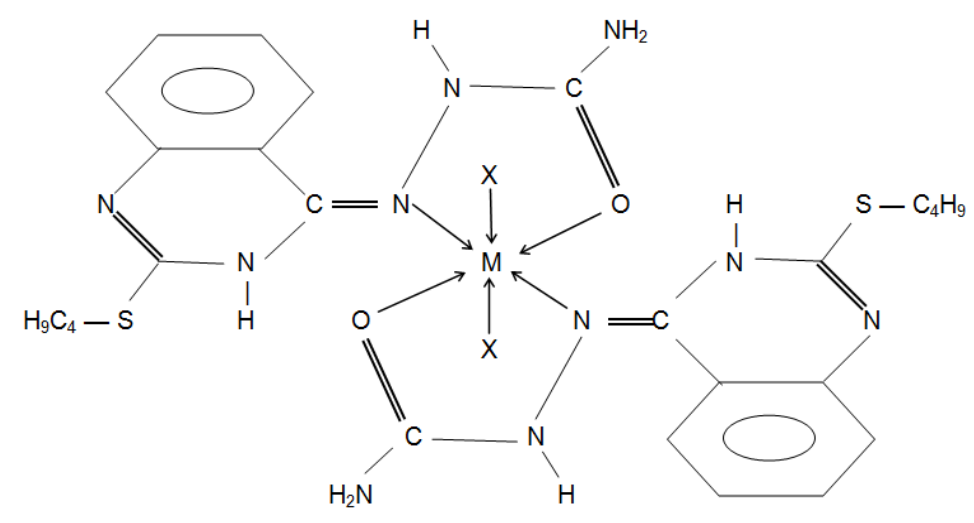

Fig. 1 [M(BTQS) $\left.)_{2}\right]$

$\mathrm{M}=\mathrm{Co}(\mathrm{II})$ and $\mathrm{Ni}(\mathrm{II}) ; \mathrm{X}=\mathrm{Cl}-\mathrm{Br}, \mathrm{I}$ or $\mathrm{NO}_{3}^{-}$.

$\mathrm{M}=\mathrm{Cu}(\mathrm{II}) ; \mathrm{X}=\mathrm{Cl}, \mathrm{Br}$ or $\mathrm{NO}_{3}$. 
RAl et al., Orient. J. Chem., Vol. 30(3), 1411-1415 (2014)

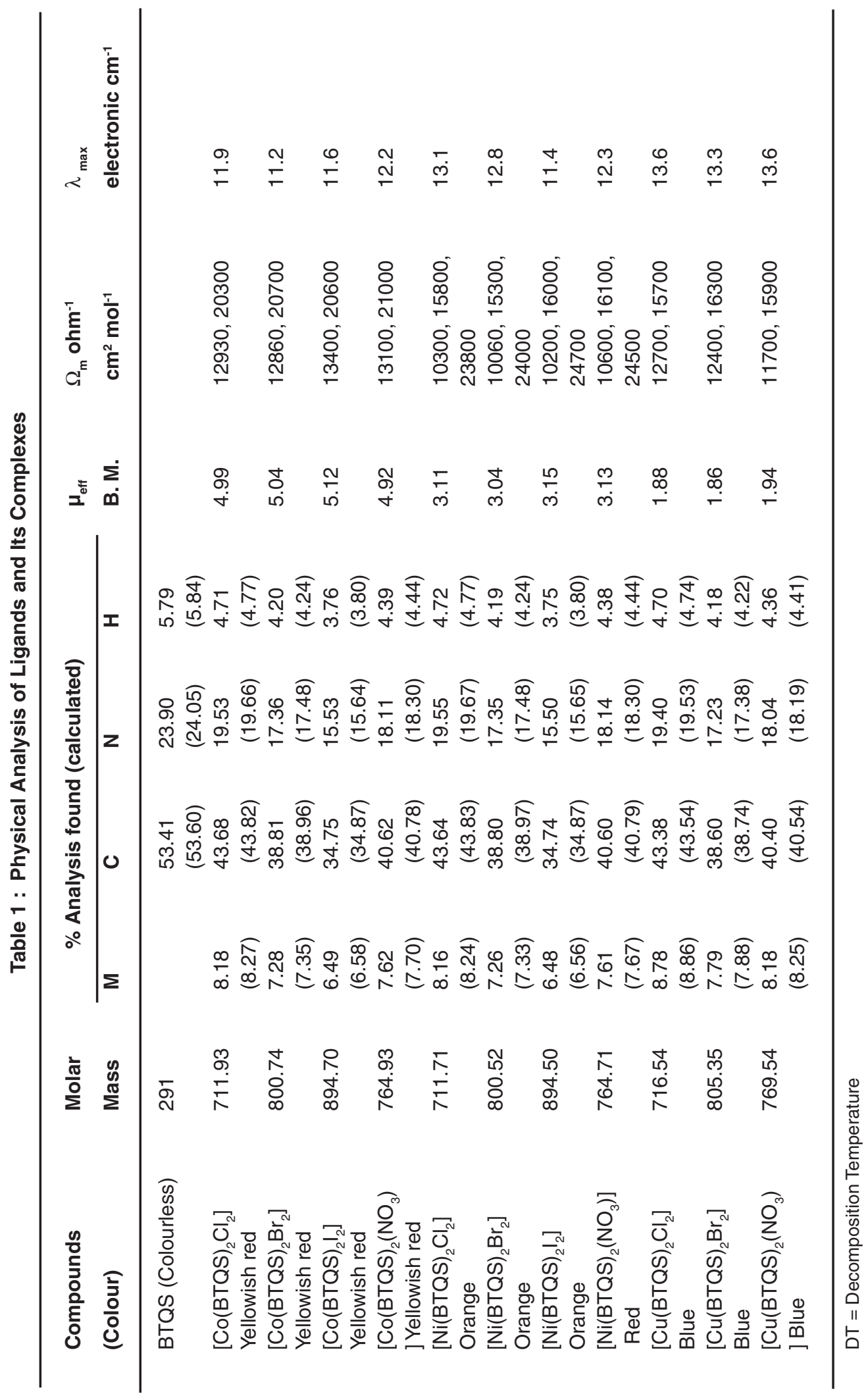


Table 2 : IR spectral bands of ligand BTQS and its metal complexes

\begin{tabular}{lcllll}
\hline Compounds & $v_{\mathrm{C}=\mathrm{O}}$ & $v_{\mathrm{C}=\mathrm{N}}$ & $v_{\mathrm{M}-\mathrm{O}}$ & $v_{\mathrm{M}-\mathrm{N}}$ & $v_{\mathrm{M}-\mathrm{X}}$ \\
\hline BTQS & $1760 \mathrm{~s}, \mathrm{~b}$ & $1560 \mathrm{~s}, \mathrm{~b}$ & & & \\
{$\left[\mathrm{Co}(\mathrm{BTQS})_{2} \mathrm{Cl}_{2}\right]$} & $1735 \mathrm{~m}, \mathrm{~b}$ & $1530 \mathrm{~m}, \mathrm{~b}$ & $515 \mathrm{~m}$ & $410 \mathrm{~m}$ & $275 \mathrm{~m}$ \\
{$\left[\mathrm{Co}(\mathrm{BTQS})_{2} \mathrm{Br}_{2}\right]$} & $1730 \mathrm{~m}, \mathrm{~b}$ & $1530 \mathrm{~m}, \mathrm{~b}$ & $510 \mathrm{~m}$ & $410 \mathrm{~m}$ & $280 \mathrm{~m}$ \\
{$\left[\mathrm{Co}(\mathrm{BTQS})_{2} \mathrm{I}_{2}\right]$} & $1730 \mathrm{~m}, \mathrm{~b}$ & $1530 \mathrm{~m}, \mathrm{~b}$ & $525 \mathrm{~m}$ & $405 \mathrm{~m}$ & $285 \mathrm{~m}$ \\
{$\left[\mathrm{Co}(\mathrm{BTQS})_{2}\left(\mathrm{NO}_{3}\right)\right]$} & $1740 \mathrm{~m}, \mathrm{~b}$ & $1540 \mathrm{~m}, \mathrm{~b}$ & $515 \mathrm{~m}$ & $305 \mathrm{~m}$ & \\
{$\left[\mathrm{Ni}(\mathrm{BTQS})_{2} \mathrm{Cl}_{2}\right]$} & $1735 \mathrm{~m}, \mathrm{~b}$ & $1535 \mathrm{~m}, \mathrm{~b}$ & $510 \mathrm{~m}$ & $420 \mathrm{~m}$ & $300 \mathrm{~m}$ \\
{$\left[\mathrm{Ni}(\mathrm{BTQS})_{2} \mathrm{Br}_{2}\right]$} & $1735 \mathrm{~m}, \mathrm{~b}$ & $1535 \mathrm{~m}, \mathrm{~b}$ & $505 \mathrm{~m}$ & $400 \mathrm{~m}$ & $510 \mathrm{~m}$ \\
{$\left[\mathrm{Ni}(\mathrm{BTQS})_{2} \mathrm{I}_{2}\right]$} & $1735 \mathrm{~m}, \mathrm{~b}$ & $1540 \mathrm{~m}, \mathrm{~b}$ & $520 \mathrm{~m}$ & $410 \mathrm{~m}$ & $320 \mathrm{~m}$ \\
{$\left[\mathrm{Ni}(\mathrm{BTQS})_{2}\left(\mathrm{NO}_{3}\right)\right]$} & $1735 \mathrm{~m}, \mathrm{~b}$ & $1540 \mathrm{~m}, \mathrm{~b}$ & $525 \mathrm{~m}$ & $425 \mathrm{~m}$ & \\
{$\left[\mathrm{Cu}(\mathrm{BTQS})_{2} \mathrm{Cl}_{2}\right]$} & $1740 \mathrm{~m}, \mathrm{~b}$ & $1540 \mathrm{~m}, \mathrm{~b}$ & $505 \mathrm{~m}$ & $395 \mathrm{~m}$ & $290 \mathrm{~m}$ \\
{$\left[\mathrm{Cu}(\mathrm{BTQS})_{2} \mathrm{Br}_{2}\right]$} & $1740 \mathrm{~m}, \mathrm{~b}$ & $1535 \mathrm{~m}, \mathrm{~b}$ & $505 \mathrm{~m}$ & $400 \mathrm{~m}$ & $295 \mathrm{~m}$ \\
{$\left[\mathrm{Ni}(\mathrm{BTQS})_{2}\left(\mathrm{NO}_{3}\right)\right]$} & $1740 \mathrm{~m}, \mathrm{~b}$ & $1535 \mathrm{~m}, \mathrm{~b}$ & $510 \mathrm{~m}$ & $410 \mathrm{~m}$ & \\
& & & & & \\
\hline
\end{tabular}

$\mathrm{S}=$ strong; $\mathrm{m}=$ medium $; \mathrm{b}=$ broad

bands in the regions, $10600-10000 \mathrm{~cm}^{-1} 16100-$ $15300 \mathrm{~cm}^{-1}$ and $24700-23600 \mathrm{~cm}^{-1}$ assigned to the transitions, ${ }^{3} \mathrm{~A}_{2 g}(\mathrm{~F}) \rightarrow{ }^{3} \mathrm{~T}_{2 \mathrm{~g}}(\mathrm{~F}),{ }^{3} \mathrm{~A}_{2 \mathrm{~g}}(\mathrm{~F}) \rightarrow{ }^{3} \mathrm{~T}_{1 \mathrm{~g}}(\mathrm{~F})$ and ${ }^{3} A_{2 g}(F) \rightarrow{ }^{3} T_{1 g}(P)$ respectively, suggested octahedral geometry ${ }^{30,34}$ for $\mathrm{Ni}(\mathrm{II})$ complexes. The propsed geometry of $\mathrm{Ni}(\mathrm{II})$ complexes is further supported by the magnetic susceptibility value in the range 3.043.15 B.M. The $\mathrm{Cu}(\mathrm{II})$ complexes exhibit two spectral bands in the regions, $11700-12400 \mathrm{~cm}^{-1}$ and $16300-$ $15700 \mathrm{~cm}^{-1}$ assigned to the transitions, ${ }^{2} \mathrm{E}_{\mathrm{g}} \rightarrow{ }^{2} \mathrm{~T}_{2 \mathrm{~g}}$ and charge transfer band suggested octahedral ${ }^{30,35}$ geometry for the $\mathrm{Cu}(\mathrm{II})$ complexes. The magnetic susceptibility value of $\mathrm{Co}$ (II) complexes lies in the range 1.86-1.94 B.M.

\section{Molar conductance measurement}

Molar conductance value of the complexes of $\mathrm{Co}(\mathrm{II}), \mathrm{Ni}(\mathrm{II})$ and $\mathrm{Cu}(\mathrm{II})$ were found to be in the range 11.2-13.7 $\mathrm{ohm}^{-1} \mathrm{~cm}^{2} \mathrm{~mol}^{-1}$ in the DMF which proposes their non-electrolytic nature. The molar conductance values also supported the structure assigned on the basis of physico-chemical and spectroscopic measurements.

\section{CONCLUSIONS}

Thus on the basis of above mentioned studies, it is proposed that the ligand BTQS acts in a neutral bidentate manner and coordinates is proposed through azomethine nitrogen and carbonyl oxygen of semicarbozone moiety which is also supported by the literature. The remaining positions of metal ions are satisfied by negative ions such as $\mathrm{Cl}^{-}, \mathrm{Br}, \mathrm{I}^{-}$and $\mathrm{NO}_{3}$. The geometry of $\mathrm{Co}(\mathrm{II}), \mathrm{Ni}(\mathrm{II})$ or $\mathrm{Cu}(\mathrm{II})$ complexes are proposed to be octahedral on nature as given in structure-l.

\section{ACKNOWLWDGEMENTS}

The author is thankful to the University Grant Commission (U.G.C.) New Delhi for financial support for this work.

\section{REFERENCES}

1. L. David, M. Rasu, O. Cozar, D. Rusu, M. 4. Todica and C. Balam, J. Mol. Struct., 1999, 482-483, 149.

2. W. Plass, A. Pohlmann and Y. Hakan-Peter, J. Inorg. Biochol; 2001, 80, 181.

3. N. Galic, B. Peric, B. Kojic-Prodic and Z. Cimerman; J. Mol. Struct, 2001, 559, 187.
Vivekanand and N.S. Bhandari, Asian J. Chem; 2007, 19, 4225.

5. J. Singh and P. Singh, Bioinorg Chem; Appl; Article ID, 2012,104549.

6. Rai B.K., Vidyarthi S.N., Sinha Puja, singh Kalyan Chandra, Shahi Shashi Bhushan and Ojha Jayvir Sharan, OrientJ. Chem. 2012, 28, 
1365.

7. Rai B.K., Vidyarthi S.N., Amit, Singh Rabindra, Bhardwaj Nitish and Ojha Avinash, Orient J. Chem; 2012, 28, 1403.

8. Rai B.K. Sinha Puja, Vidyarthi S.N. and Singh Vineeta, Asian J. Chem., 2011, 23, 4629.

9. Rai B. K., Singh Vineeta, Vidyarthi S. N. and Sinha Puja, Asian J. Chem., 2011, 23, 4638.

10. Rai B.K., Vidhyarthi S.N., Kumari Punam, Kumari Suman, Kumari Lakshmi and Rajkishore Singh, Asian J. Chem, 2013, 25, 941.

11. Rai B.K., Anand Rahul, Asian J. Chem., 2013, 25, 480.

12. Rai B.K., Thakur Amrita and Divya, Asian J. Chem., 2013, 25, 583.

13. Rai B.K., Kumar Arun, Asian J. Chem., 2013, 25, 1187.

14. Rai B.K. J. Indian Chem., soc; 2013, 90, 105.

15. Rai B.K., Vidyarthi S.N., Sinha Puja, Singh Vineeta and Kumar Sanjiv, Orient J. Chem., 2013, 29, 271.

16. Rai B.K., Kumar Sanjay, Anand Rahul and Pandey Ashok, Orient J. Chem., 2013, 29, 655.

17. Rai B.K, Singh Rabindra, Anand Puja, Singh Sunil Kumar and Amit, Orient J. Chem., 2013, 29, 753.

18. Rai B.K., Vidyarthi S.N., Prakash Om and Baluni, Akhilesh Orient J. Chem; 2013, 29, 801.

19. Choudhry Chitranjan Prasad, Sharma S.P., Rai C.L. and Rai B.K., Orient J. Chem., 2013, 29, 963.

20. Rai B.K., Kumari Rachna, Orient J. Chem., 2013, 29, 1163.

21. Rai B.K. and Kumar Arun, Orient J, Chem, 2013, 29, 1187.
22. Vogel, Textbook of Quantitative Chemical Analysis, Revised by Mendham J., Denny R.C., Barenes J.P. and Thomas M., Pearson Education 2008.

23. Mishra A.P., Purwar H. and Jain R.K., Biointerface Res. Appl. Chem, 2012, 2, 291.

24. Silverstein Rober and Webster Francis, "Spectrometric Identification of Organic Compounds", $6^{\text {th }}$ Ed. John-Wiley and Sons, 2008.

25. Kemp William, Organic Spectroscopology, $3^{\text {rd }}$ Edn., Polgrove, New York, 2008)

26. Ferraro J.R., 'Low Frequency Vibration of Inorganic and Coordination Compound", Plenum Press, New York.

27. Reddy K. Laxman and Upendra S., Indian J. Chem., 2000, 39A, 1202.

28. Rao C.N., Chemical application of IR Spectroscopy, Academic Press, New York, 1963, 206.

29. Addition C. C. Logan N. Wallwork S. C. and Barmer D. C., Quart. Rev., 1971)

30. Lever, A.B.P. Inorganic Electronic spectroscopy, Elsevier, Amsterdam, 1968, 395.

31. Mane P.S. Shirodhar S.G., Arbad B.R. and Chandekar T.K., Indian J. Chjem., 2000, 40A, 648.

32. Figgis B.N., Introductio to Ligand Field, Wiley Eastern Ltd., New Delhi, 1976, 279.

33. Carlin R.L. and Van Dryneveldt a.J. Magnetic Properties of Transition metal compounds, springer verlag, NewYork 1997.

34. Tahir A.K., Shivanjal, Nafees J. and Shoukat K., Indian J. Chem., 2000, 39A, 450.

35. Mishra A.P., Khare M and Gauta, S.K., Synth. React. Inorg. Met. Org. Chem. 2002, 32, 1485. 